\title{
Potenciais Impactos de Sistemas Estáticos de Esgotamento Sanitário na Água Subterrânea - Revisão de literatura
}

\author{
Sílvia M. A. Corrêa Oliveira, Marcos von Sperling \\ Universidade Federal de Minas Gerais \\ silvia@desa.ufmg.br; marcos@desa.ufmg.br
}

Recebido: 18/01/10 - revisado: 03/09/10 - aceito: 17/08/11

\begin{abstract}
RESUMO
Esta revisão de literatura efetua uma compilação de diversos estudos que investigaram os potenciais impactos de sistemas estáticos de esgotamento sanitário na contaminação da água subterrânea, principalmente por nitrato e organismos patogênicos. Algumas conexões claras foram relatadas em diversos estudos, mas o grau e o impacto de tais contaminações foram pouco esclarecidos. A extensão da contaminação é extremamente variável e pode ser função das condições do solo, tipo de sistema de tratamento, taxas de aplicação de esgoto, características do aquífero e profundidade do nível d'água. Consequentemente, o projeto, a construção e a manutenção adequada destes sistemas são cruciais para uma operação sustentável e bem sucedida. As evidências de contaminações de aquíferos parecem ser baseadas mais no aumento do número de sistemas estáticos em todo o mundo do que nos problemas efetivamente observados e que sejam diretamente associados a este tipo de tecnologia.
\end{abstract}

Palavras-chave: Sistemas estáticos de esgotamento, água subterrânea, contaminação, organismos patogênicos, nitrato.

\section{INTRODUÇÃO}

Aproximadamente 1,1 bilhão de pessoas permanece sem acesso a fontes seguras de água e cerca de 2,4 bilhões, quase metade da população mundial, não possuem nenhum tipo de serviço de esgotamento sanitário, apesar dos enormes avanços observados no século anterior. Como consequência, 2,2 milhões de pessoas em países em desenvolvimento, a maioria crianças, morrem todo ano de doenças associadas a precárias condições de saneamento básico (WHO/UNICEF, 2005).

Uma disposição adequada de dejetos é de suma importância para a saúde e o bem-estar de todos os seres humanos, envolvendo também aspectos sociais e ambientais. Existe um grande número de doenças relacionadas com fezes humanas infectadas por bactérias, vírus, protozoários e helmintos. As maiores incidências, geralmente relatadas, dizem respeito a infecções intestinais e infestações por helmintos, incluindo cólera, febres tifóide e paratifóide, diarréia, esquistossomose, entre outras (WHO, 1992, Argoss, 2001).

Além do conteúdo patogênico, a composição química dos esgotos também deve ser conside- rada devido ao seu efeito sobre a saúde da população. O número de componentes a serem monitorados (por exemplo, metais pesados, compostos orgânicos, detergentes, etc.) é maior em áreas urbanas industrializadas do que em áreas rurais. No entanto, a concentração de nitrato $\left(\mathrm{NO}_{3}^{-}\right)$é importante em todas as áreas, devido à possibilidade de sua acumulação em águas superficiais e subterrâneas, seu efeito na saúde humana (metahemoglobinemia em lactentes e alguns tipos de câncer) e no equilíbrio ecológico de águas receptoras de efluentes. Embora a maior fonte antrópica de contaminação por nitrato esteja associada aos fertilizantes nitrogenados em áreas rurais, a falta de serviços adequados de esgotamento sanitário pode contribuir e, em casos excepcionais, se constituir no maior fator de elevação de concentrações de nitrato, principalmente em águas subterrâneas (WHO, 1992; Harman et al., 1996; Dillon et al., 2000; Steffy e Kilham, 2004).

Tais aspectos têm motivado um grande número de pesquisas sobre a contaminação de águas subterrâneas por sistemas estáticos de tratamento de esgotos domésticos, principalmente aqueles que possuem uma etapa de disposição no solo como parte integrante do processo. Os riscos têm aumentado devido à crescente utilização destes sistemas, e 
também devido à sua inadequada manutenção, principalmente em países em desenvolvimento. No entanto, mesmo países desenvolvidos fazem uso deste tipo de sistema de tratamento e disposição de esgotos.

Beal et al. (2005) comentam que mais de um milhão de residências (mais de dois milhões e seiscentas mil pessoas) na Austrália utilizam sistemas estáticos e que nos Estados Unidos o número é superior a 60 milhões de pessoas. Relatam ainda que, na atualidade, em alguns países em desenvolvimento o percentual chega a atingir $100 \%$.

Neste cenário, o presente trabalho objetiva apresentar uma compilação de diversos estudos que investigaram os potenciais impactos de sistemas estáticos de esgotamento sanitário na água subterrânea, principalmente por nitrato e organismos patogênicos. Foi feita a opção de se sintetizar os estudos na forma de quadros-resumo, que são consolidados, comentados e representam a maior parte deste trabalho.

\section{SISTEMAS ESTÁTICOS DE ESGOTAMENTO}

Os sistemas estáticos podem ser constituídos por opções de baixo custo, tais como várias formas de fossas (seca e absorvente, dentre outras), ou opções de custo mais alto, como tanques sépticos. Os sistemas que utilizam a disposição local dos dejetos podem ser classificados ainda quanto à ausência ou à presença de transporte hídrico. Assim, a fossa seca faria parte do primeiro grupo, exigindo solução independente para a disposição das águas servidas, enquanto a fossa séptica, que prevê o transporte hídrico dos dejetos, faria parte do segundo (Heller e Chernicharo, 1996).

Para cada comunidade, deve ser escolhida a opção mais factível e conveniente para fornecer a proteção necessária à saúde e ao meio ambiente. Para a seleção da opção mais apropriada, uma ampla análise deve ser efetuada, considerando fatores como custo, aceitação cultural, simplicidade de projeto e construção, operação e manutenção, assim como disponibilidade local de materiais e tecnologias. Além dos aspectos construtivos e operacionais, cabe também salientar os aspectos hidrogeológicos tais como tipo de aquífero, profundidade do nível d’água, litologia, espessura da zona não-saturada, entre outros (WHO, 1992, Franceys et al., 1992; Cotton e Saywell, 1998).

Nos sistemas estáticos de esgotamento, em geral, os esgotos são tratados primariamente na própria fossa, via sedimentação e digestão anaeróbia. Em seguida, o efluente é infiltrado no solo circunvizinho, que é utilizado como meio de tratamento e de dispersão. Neste tipo de sistema de tratamento são utilizados processos biogeoquímicos naturais, que ocorrem no solo para assimilar os vários poluentes infiltrados. A sua vantagem em relação a outros métodos é a relativa simplicidade, baixo custo e, se construídos apropriadamente, sua capacidade de tratamento. As desvantagens estão relacionadas à variabilidade e heterogeneidade inerente ao solo e aos processos biogeoquímicos. Diferentemente das estações de tratamento de esgotos, que empregam, em geral, processos que podem ser controlados ou regulados diretamente após a instalação do sistema, a operação dos sistemas estáticos não permite intervenções. Consequentemente, um projeto e uma construção apropriados são cruciais e devem ser baseados em conhecimento prévio das condições do local e do solo, para uma operação sustentável e bem sucedida destes sistemas (Day, 2004; Beal et al., 2005b, Murray et al., 2007, Katz e Griffin, 2008).

\section{POTENCIAIS IMPACTOS DE SISTEMAS ESTÁTICOS NA ÁGUA SUBTERRÂNEA}

O líquido que percola das fossas para o solo contém um grande número de microrganismos de origem fecal (podendo incluir patogênicos), nitrogênio (convertido a nitrato no solo) e outros sais. Como consequência, a água subterrânea que recebe o percolado das fossas poderá se tornar contaminada, com potenciais problemas caso essa água venha a ser usada diretamente para abastecimento público ou domiciliar. Também, caso haja problemas de subpressão nas redes de abastecimento de água devido a intermitências no abastecimento, poderá haver entrada de água subterrânea contaminada na rede, podendo comprometer a qualidade da água fornecida à população.

Com relação à poluição química, esta se estende muito além daquela provocada por microrganismos. Quando existe grande densidade de fossas e de tanques sépticos, as concentrações de nitrato podem atingir valores muito acima daquele recomendado pela Organização Mundial da Saúde (OMS) e pela Portaria 518/2004 do Ministério da Saúde para águas potáveis $(10 \mathrm{mgN} / \mathrm{L})$. As reações de formação do nitrato ocorrem em meio aeróbio, sendo observados, primeiramente, os processos de fixação do nitrogênio orgânico e posterior conver- 
são deste a amônio (amonificação). Este, através das reações de nitrificação é convertido a nitrito e, a seguir, a nitrato.

Geralmente, é necessário avaliar os riscos de contaminação e o nível de degradação aceitável na qualidade da água. Em alguns casos, a contaminação de águas subterrâneas por sistemas estáticos pode não ser ameaça para a saúde porque outras fontes de abastecimento são utilizadas, ou quando a eficiência de filtração do solo é suficiente para eliminar os microrganismos patogênicos.

A literatura sobre poluição de água subterrânea, em geral, relata que se existirem dois metros ou mais de areia ou terra entre o fundo de uma fossa ou campos de infiltração e a água subterrânea, virtualmente todas as bactérias, vírus e outros organismos fecais são removidos (USEPA, 1977; Gonda, 1985; Alhajjar et al., 1988, Chidavaenzi et al., 2000; Lipp et al., 2001; Howard et al, 2006a). Considerando uma distância segura entre a localização de uma fossa e de poços de abastecimento, os autores alertam, principalmente, para a importância da permeabilidade do solo, sendo reportados valores que variaram de seis a 22,5m (Gonda, 1985; Lipp et al., 2001, Pang et al., 2003). No entanto, Vaughn et al. (1983) criticam a adoção indiscriminada de critérios fixos, sugerindo que as distâncias devem ser estabelecidas com base nas condições hidrogeológicas locais (como profundidade do nível d’água, natureza da zona não-saturada) e na carga hidráulica aplicada na fossa. Tal recomendação é corroborada pela pesquisa desenvolvida por Yates et al. (1986) que, utilizando uma técnica geoestatística para calcular as distâncias entre poços de abastecimento e fontes de contaminação por vírus, chegaram a valores compreendidos entre 15 e $150 \mathrm{~m}$, em função do gradiente hidráulico e da condutividade hidráulica observados na área de estudo. Howard et al. (2006b) também relatam estudos efetuados na África do Sul, onde foram propostos procedimentos para estabelecer tais distâncias em função da avaliação de risco de contaminação, considerando a localização e tipo do aquífero, o uso proposto para a água subterrânea, a presença de fossas já existentes e a evidência de contaminação. Os autores mencionam, ainda, outro trabalho efetuado para estimar o risco de poluição, que propõe levar em conta o tempo de locomoção dos microrganismos, o balanço de massa para nitrato e, ainda, utilizar uma abordagem probabilística para avaliar se a contaminação excederá certos padrões especificados.

\author{
Impactos ambientais e na saúde humana \\ decorrentes de fontes de nitrogênio associadas \\ aos sistemas de esgotamento estático
}

A sensibilidade dos consumidores de água contendo nitrato com relação à metahemoglobinemia parece estar relacionada ao $\mathrm{pH}$ estomacal das crianças (igual ou maior do que 4). Nestas condições as bactérias redutoras de nitrato se desenvolvem no intestino delgado, reduzindo o nitrato a nitrito, que é absorvido pela corrente sanguínea, convertendo a hemoglobina a metahemoglobina. $\mathrm{O}$ pigmento alterado, não transportando com eficiência o oxigênio, provoca a asfixia (Gonda, 1985).

Tanto falhas hidráulicas quanto de tratamento podem ocorrer a partir de uma má operação de sistemas estáticos de tratamento de esgotos. As falhas hidráulicas (sobrecarga) ocorrem quando as taxas de infiltração através do biofilme são excedidas pelas taxas de aplicação do efluente da fossa, ou seja, quando o solo que circunvizinha o sistema não consegue absorver o líquido tão rapidamente quanto este é gerado, resultando em descarga de efluente na superfície do solo. Estudos têm mostrado que tal problema é relativamente comum em sistemas antigos e/ou mal operados (Geary e Whitehead, 2001; Hogye et al., 2001; Lipp et al., 2001; Day, 2004).

As falhas de tratamento são menos óbvias e são fortemente associadas aos processos biogeoquímicos do solo. Um nível d’água raso e/ou um subsolo saturado podem resultar em um efluente tratado inadequadamente, entrando em contato com a água subterrânea. O tempo de detenção hidráulica curto e as condições aeróbias reduzidas que ocorrem nestas circunstâncias impedem um tratamento adequado do efluente antes do contato com a água subterrânea. As duas formas de falha podem resultar em contaminação de águas superficiais e subterrâneas, conforme relato apresentado em diversos estudos efetuados e apresentados no Quadro 1.

Como observado em grande parte das pesquisas efetuadas, o nitrato tem sido reportado como o contaminante mais encontrado, em elevadas concentrações, em águas subterrâneas e associado a sistemas estáticos (Harman et al., 1996; Steffy e Kilham, 2004). No entanto, existem poucos registros de toxicidade por nitrato associados a tais sistemas. L'Hirondel e L'Hirondel (2002), apud Beal et al. (2005), efetuaram uma análise crítica da evidência de metahemoglobinemia induzida por águas de poços. Eles concluíram que existe uma baixa correlação entre altas concentrações de nitrato em águas de poços e ocorrência de metahemoglobinemia 
Quadro 1 - Síntese de pesquisas que investigaram a contaminação de águas subterrâneas, por nitrato, a partir de sistemas com disposição no solo

\begin{tabular}{|c|c|}
\hline Referência & Síntese da pesquisa \\
\hline $\begin{array}{l}\text { Harman } \\
a l ., 1996\end{array}$ & $\begin{array}{l}\text { Cerca de } 400 \text { amostras de águas subterrâneas de um aquí- } \\
\text { fero livre usadas para delinear a pluma de um efluente de } \\
\text { um TAS de } 44 \text { anos, instalado em uma escola em Ontário, } \\
\text { Canadá. }\end{array}$ \\
\hline
\end{tabular}

Impactos relacionados com o sistema estático de tratamento

Os traçadores de brometo $\left(\mathrm{Br}^{-}\right)$indicaram um tempo de detenção do efluente de uma a duas semanas no solo não saturado do TAS $(1,6 \mathrm{~m})$. Tempo suficiente para oxidar todo o $\mathrm{N}^{2} \mathrm{NO}_{3}^{-} \mathrm{e}$ reduzir as concentrações efluentes de $\mathrm{PO}_{4}{ }^{3-}$ de 9 para 1-2 mg/L.O estudo não indicou eutrofização prévia ou existente na região. Os autores concluíram que as concentrações de nitrato em toda a extensão da pluma $(110 \mathrm{~m})$ estavam acima dos padrões de potabilidade. Outra conclusão apontada foi a de que os sistemas sépticos constituíam a principal fonte de contaminação por nitrato de cerca de $30 \%$ dos poços privados, contaminados.

Os resultados indicaram que as concentrações de

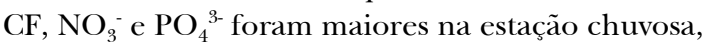
devido provavelmente, à posição do nível d'água (raso), ao tipo de solo e à ausência de manutenção dos TS. Os autores atribuíram este comportamento também aos processos de diluição.

Taxas de transporte e direção podem diferir devido a mudanças na geologia local e influência das marés. A eutrofização na área foi estudada. Contribuição parcial dos sistemas de disposição local de esgotos, mas não foram estimadas as cargas de outras áreas.

Autores concluíram haver risco potencial de contaminação quando houver 15 ou mais sistemas estáticos $/ \mathrm{km}^{2}$ em uma região. Estudo não reportou eutrofização da área em estudo.

O estudo indicou contaminação por nitrato proveniente do sistema de fossa séptica com valores acima do limite de $45 \mathrm{mg} / \mathrm{L} \mathrm{NO}_{3}^{-}$. O estudo não indicou eutrofização prévia ou existente na região. Os autores identificaram ainda que as concentrações de nitrato, assim como demais parâmetros físico-químicos variavam, sazonal e espacialmente, em decorrência dos efeitos da rápida recarga e heterogeneidade do aquífero.

Vários TAS situados em solos inadequados apresentaram problemas operacionais. Outros TAS eram antigos ou foram utilizados além de sua capacidade. Não foi verificada contaminação por P devido, principalmente, às grandes distâncias observadas das águas superficiais. 
Quadro 1 - Síntese de pesquisas que investigaram a contaminação de águas subterrâneas, por nitrato, a partir de sistemas com disposição no solo (continuação)

\begin{tabular}{ll}
\hline Referência & \multicolumn{1}{c}{ Síntese da pesquisa } \\
\hline Faye et al., & $\begin{array}{l}\text { Comparados dados de qualidade de água de } 56 \text { poços, } \\
\text { características dos aquíferos, tipos de solos e usos da terra } \\
\text { na cidade de Dakar, no Senegal, para avaliar a vulnerabi- } \\
\text { lidade da qualidade da água subterrânea. }\end{array}$ \\
\hline
\end{tabular}

Fontes de $\mathrm{NO}_{3}^{-}$em aquíferos rasos em 21 áreas urbanas Jin et al., de Hangzhou, China foram investigadas usando técnicas 2004 químicas e isotópicas. Quatro análises mensais de $\mathrm{Na}^{+}$, $\mathrm{Ca}^{2+}, \mathrm{K}^{+}, \mathrm{Mg}^{2+}, \mathrm{NH}_{4}^{+}, \mathrm{NO}_{2}^{-}, \mathrm{NO}_{3}^{-}, \mathrm{Cl}^{-}$e $\mathrm{SO}_{4}{ }^{2-}$ foram efetuadas entre novembro/2001 e fevereiro/2002.

Proposição de uma abordagem integrada de risco para Carroll et al. avaliar os perigos associados a sistemas estáticos de trata2006 mento, em particular TS. É apresentado um estudo de caso efetuado para uma região do estado de Queensland, Austrália, que possui cerca de 15.000 TS.

Coletadas amostras mensais de água subterrânea em 12 poços situados em áreas rurais da Coréia (1997 - 1999),

Choi et al., ao longo de três anos, com o objetivo de examinar os 2006 efeitos de diferentes usos da terra na contaminação por $\mathrm{NO}_{3}^{-}$, considerando a concentração deste contaminante e valores de $\delta^{15} \mathrm{~N}$.

Estudo mediu as concentrações de $\mathrm{N}$ e valores de $\delta^{15} \mathrm{~N}$ em Cole et al., águas infiltradas em três lagoas e seis estuários em Cape 2006 Cod, Massachusetts, EUA, para avaliar como eles variavam com os diferentes tipos de uso da terra. Al- rânea da região de Petra, Jordânia, durante três anos

Estudo avaliou a qualidade físico-química da água subterKhashman, (setembro/2002 a setembro/2005). Foram analisados: 2007 condutividade elétrica, oxigênio dissolvido, $\mathrm{pH}, \mathrm{Ca}^{2+}$, $\mathrm{Mg}^{2+}, \mathrm{K}^{+}, \mathrm{Na}^{+}, \mathrm{Cl}^{-}, \mathrm{NO}_{3}{ }^{-}, \mathrm{HCO}_{3}{ }^{-}, \mathrm{SO}_{4}^{-2}, \mathrm{PO}_{4}^{-3} \mathrm{e} \mathrm{F}^{-}$.

Estudo avaliou o risco de contaminação por $\mathrm{NO}_{3}^{-}$em um aquífero no sul da Itália, quanto ao uso da terra, desenCorniello et volvimento urbano e características do aquífero. Foi utilial., 2007 zado o SIG para traçar mapas de risco de contaminação por nitrato e efetuada correlação com a concentração de nitrato do aquífero.

Foram coletadas 69 amostras para identificar processos de contaminação de água subterrânea em uma região ocidental do Irã, que possui características hidrogeoquímicas complexas. A água subterrânea é utilizada para abastecimento e para fins domésticos, industriais e, principalmente, agrícolas.

\section{Impactos relacionados com o sistema estático de} tratamento

A contaminação por nitrato em algumas regiões foi consequência de fontes pontuais originadas de tanques sépticos mal construídos na área. Em outras partes do aquífero, elevadas concentrações de $\mathrm{NO}_{3}{ }^{-}$foram atribuídas à atividade agrícola.

Os estudos indicaram a presença de diferentes fontes antrópicas de contaminação por nitrato. Em áreas residenciais, a fonte predominante de nitrato foi o esgoto doméstico, mas apenas dois poços mostraram a influência de efluentes de tanques sépticos.

Os riscos ambientais e de saúde pública identificados foram, na maioria, decorrentes da utilização de solos inapropriados, o que resultou em um aumento de falhas nos sistemas e subsequente contaminação de fontes de água.

Contaminação por nitrato observada continuará a se espalhar enquanto práticas agrícolas adotadas na região se mantiverem. $\mathrm{Na}$ área residencial a maior fonte de contaminação foi atribuída aos efluentes de tanques sépticos ou vazamentos em redes de coleta, mas estudos complementares seriam necessários para confirmação.

As concentrações de nitrato e os valores de $\delta^{15} \mathrm{~N}$ na água subterrânea foram muito variados e maiores em bacias mais populosas. Os maiores contribuintes de nitrogênio foram identificados como os efluentes de TS.

Os constituintes inorgânicos da água foram influenciados por fontes naturais e antrópicas e indicaram que algumas amostras estavam fortemente poluídas com $\mathrm{NO}_{3}{ }^{-}$e $\mathrm{SO}_{4}{ }^{2-}$. Possíveis fontes de poluição seriam atividades agrícolas e percolação de fossas e TS.

Os resultados mostraram que as fontes de nitrato na água subterrânea não eram apenas de práticas agrícolas e criação intensiva de gado, mas também de vazamentos de redes coletoras de esgoto e de efluentes de tanques sépticos antigos.

As concentrações de nitrato de 17 amostras (26\%) foram maiores que o valor das diretrizes da OMS. A água subterrânea parece ter sido poluída pela aplicação de fertilizantes, práticas de irrigação, solubilidade de minerais e contribuição de esgotos domésticos advindos de tanques sépticos.

Nota: TAS: Sistema de tanque séptico seguido de absorção no solo; TS: tanque séptico 
infantil. Elevadas concentrações de nitrato em águas de poços têm sido associadas a privadas e fossas absorventes, mas existem poucos estudos correlacionando sistemas estáticos convencionais à metahemoglobinemia. Os autores recomendam que, mesmo que existam evidências de associação de elevadas concentrações de nitrato em águas subterrâneas e efluentes de sistemas estáticos, a suposição de que tais concentrações causam problemas para a saúde humana não pode ser automática e existem poucas evidências científicas para dar suporte a tais conclusões.

\section{Impactos na saúde humana decorrentes de organismos patogênicos associados aos sistemas de esgotamento estático}

O Quadro 2 apresenta resultados de diversos estudos sobre a contaminação microbiológica decorrente de sistemas de esgotamento estático, principalmente em águas subterrâneas, e seu impacto na saúde humana. Grande parte dos estudos utiliza indicadores de contaminação fecal, como os coliformes termotolerantes (CF) e estreptococos fecais $(\mathrm{EF})$, visando com isso inferir sobre a eventual presença de vírus e bactérias patogênicas. As doenças mais comumente relatadas nos trabalhos consultados foram as diarréias viral e bacteriana, enteroviroses infecciosas, febre tifoide e outras de características similares.

A preocupação com a contaminação microbiológica por sistemas estáticos de tratamento, principalmente em águas subterrâneas, tem crescido muito nos últimos anos. No entanto, van Cuyk e Siegrist (2001) sugerem que esta preocupação está baseada mais no aumento do número de sistemas estáticos utilizados em todo o mundo do que nos problemas efetivamente observados. Nos locais onde foram verificadas associações entre doenças de veiculação hídrica e sistemas estáticos de tratamento, estes eram simples e mal operados (Lipp et al., 2001; Bopp et al., 2003, Meeroff et al., 2008). Os impactos cumulativos do aporte de organismos patogênicos sobre a saúde humana não têm sido adequadamente investigados e/ou reportados devido a dificuldades econômicas e logísticas para este tipo de pesquisa, mas modelos mais complexos de qualidade das águas, alguns baseados em análise de risco, têm se mostrado ferramentas úteis e utilizados por vários pesquisadores (Tong e Chen, 2002; Carroll et al., 2006, Corniello et al., 2007).

\section{DENSIDADE DE SISTEMAS ESTÁTICOS}

Um fator essencial para um gerenciamento sustentável de sistemas estáticos de tratamento de esgotos é a existência de área suficiente para a assimilação e redução da poluição. À medida que cresce o número de unidades descentralizadas de esgotamento por fossa/infiltração, maior é o potencial para impactos adversos na água subterrânea, tais como contaminação cumulativa da qualidade da água (nitrato) e elevação do nível d’água dos aquíferos (Siegrist et al., 2000). A distância entre unidades deve ser suficiente para permitir a assimilação dos efluentes pelo solo. No entanto, a determinação específica das distâncias mínimas e da densidade máxima é naturalmente dificultada pelas diferenças existentes em cada local, em função das características do solo e do esgoto aplicado. As pesquisas efetuadas sugerem o já esperado fato de que uma maior densidade de sistemas estáticos acarreta um aumento na carga poluidora de nitratos e organismos patogênicos recebida pela água subterrânea (Tuthill $e t$ al., 1998; Geary e Whitehead, 2001; Lipp et al., 2001; Borchardt et al., 2003; Pradhan et al., 2004). Assim, a determinação do valor da densidade de sistemas estáticos que seja sustentável é um fator crítico, apesar da dificuldade inerente a seu estabelecimento.

A despeito das dificuldades comentadas, algumas tentativas de quantificação da densidade máxima recomendada têm sido efetuadas por diversos pesquisadores (Yates et al., 1986; Geary e Gardner, 1998; Jelliffe, 1999; Geary e Whitehead, 2001). Uma densidade maior que 15 sistemas $/ \mathrm{km}^{2}$ foi reportada como insustentável, baseada em um estudo efetuado nos Estados Unidos pela EPA em 1977 e citada por Yates (1985). Neste tipo de estudo, foram consideradas as taxas de percolação e a capacidade de absorção do solo. No entanto, Whitehead et al. (2001) comentam que tal suposição foi baseada em um número insuficiente de dados. Jelliffe (1999) sugere que as distâncias recomendadas devem variar com o tipo de solo e com os padrões de qualidade da água subterrânea, e propõe um modelo biofísico para calcular uma área suficiente para a assimilação dos nutrientes. Uma síntese de alguns tamanhos mínimos e densidades recomendadas na literatura para os sistemas centralizados de tratamento foi elaborada por Beal et al. (2005b) e é reproduzida no Quadro 3.

A Norma Brasileira (NBR 13969/97) estabelece que o número máximo de sistemas compostos por tanque séptico e vala de infiltração deve ser limitada a 10 unidades/ha $\left(=1000\right.$ unidades $\left./ \mathrm{km}^{2}\right)$ 
Quadro 2 - Síntese de pesquisas que investigaram contaminação de águas subterrâneas, por organismos patogênicos, a partir de sistemas com disposição no solo

\begin{tabular}{|c|c|}
\hline Referência & $\begin{array}{l}\text { Impactos relacionados com o sistema estático de } \\
\text { tratamento }\end{array}$ \\
\hline t al., 1988 & $\begin{array}{l}\text { Avaliado o potencial de contaminação de amos- } \\
\text { tras de água subterrânea por efluentes de } 17 \text { TS Os parâmetros biológicos (CT, CF e EF) foram } \\
\text { no centro-sul de Wisconsin, EUA. Foram utiliza- retidos pelo solo, mas os poliovírus foram detecta- } \\
\text { dos indicadores químicos (Cl, condutividade dos nas águas subterrâneas, mesmo com o bom } \\
\text { elétrica) e biológicos (coliformes totais - CT, funcionamento do tanque séptico. Resultados } \\
\text { coliformes termotolerantes - CF e estreptococos mostram que CT, CF e EF não são bons indicado- } \\
\text { fecais - EF), além de poliovírus introduzidos em res da presença dos vírus. } \\
\text { um dos sistemas. }\end{array}$ \\
\hline $\begin{array}{l}\text { DeBorde et al. } \\
1998\end{array}$ & 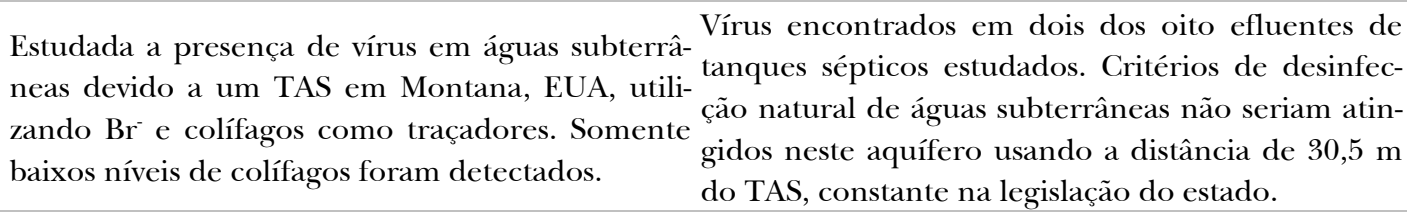 \\
\hline Tuthill et al., 1998 & $\begin{array}{ll}\text { Pesquisa em Maryland, EUA. } 832 \text { poços de abas- Contaminação fecal e por nitrato foi maior quando } \\
\text { tecimento foram analisados quanto à presença de } \\
\begin{array}{ll}\text { CF e nitrato, encia entre o poço e o sistema de tratamento } \\
\text { e entre o fundo da fossa e o nível da água subter- } \\
\text { rânea diminuíam. }\end{array}\end{array}$ \\
\hline $\begin{array}{l}\text { Harrison et } \\
2000\end{array}$ & $\begin{array}{l}\text { Avaliada a qualidade da água entre } 0,3 \text { e } 0,9 \mathrm{~m} \text { de } \\
\text { profundidade, abaixo de três TS instalados em Nestas profundidades, os efluentes dos tanques } \\
\text { solos de alta permeabilidade em Pierce County, sépticos não atendem aos padrões de qualidade de } \\
\text { Washington -EUA, onde existe grande densidade água do estado, considerando todos os parâmetros. } \\
\text { de sistemas. Foram analisados os parâmetros: } \mathrm{CF} \text {, O autor sugere a implantação de filtros de areia } \\
\mathrm{NO}_{2}^{-}, \mathrm{NO}_{3}{ }^{-}, \mathrm{NH}_{4}{ }^{+} \text {e NTK (N orgânico }+\mathrm{N} \text { amonia- como pós-tratamento para amenizar o problema. } \\
\text { cal). }\end{array}$ \\
\hline Lipp et al., 2001 & $\begin{array}{l}\text { Análise do impacto de grande densidade de sis- } \\
\text { temas estáticos na contaminação fecal de águas } \\
\text { nateroviroses infecciosas detectadas ao longo da } \\
\text { na costa da Flórida, EUA. Análises multivariadas cestudo parecem estar associadas à presen- } \\
\text { para verificação dos riscos indicaram a relação postemas estáticos de tratamento, mas não foi } \\
\text { entre alta densidade de sistemas com a poluição. }\end{array}$ \\
\hline Nicosia et al., 2001 & 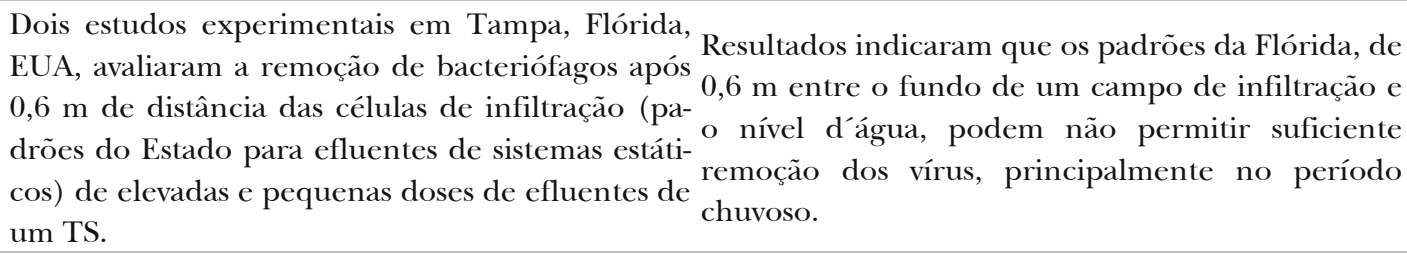 \\
\hline Bopp et al., 2003 & 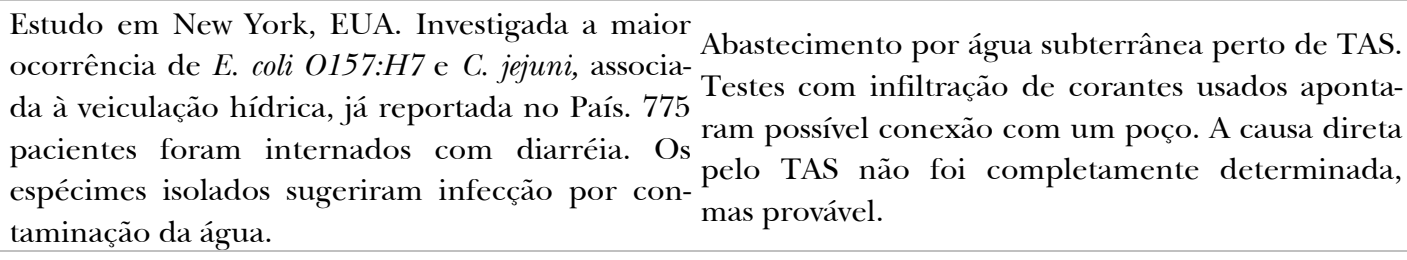 \\
\hline $\begin{array}{l}\text { Borch } \\
2003\end{array}$ & 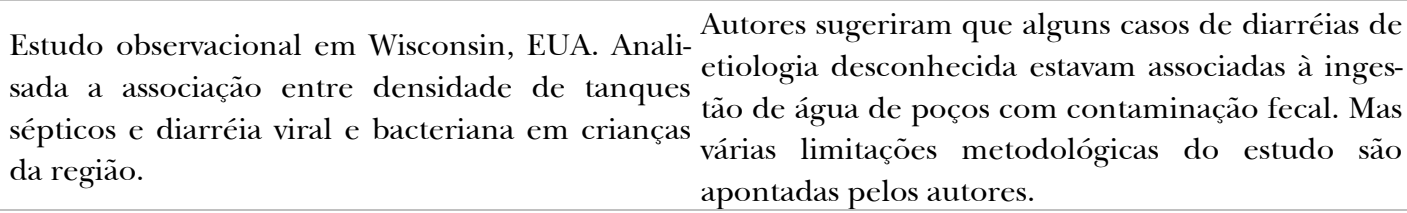 \\
\hline
\end{tabular}


Quadro 2 - Síntese de pesquisas que investigaram contaminação de águas subterrâneas, por organismos patogênicos, a partir de sistemas com disposição no solo (continuação)

\begin{tabular}{ccc}
\hline Referência & Síntese da pesquisa & $\begin{array}{c}\text { Impactos relacionados com o sistema estático de } \\
\text { tratamento }\end{array}$ \\
\hline
\end{tabular}

Estudo em Carolina do Sul, EUA, num período

de 10 anos. Análises de regressão indicaram cor- Apesar da correlação observada, pesquisas indica-

Kelsey et al, 2004 relação entre proximidade de áreas com TAS e ram que a poluição fecal não tinha origem humacontaminação fecal. Foi utilizado SIG para avaliar na. Parece ter havido coincidência entre proximia associação entre uso da terra e presença de CF dade dos TAS e contaminação.

no estuário.

Análise de componentes principais foi usada para Alta densidade de sistemas pode impactar significaavaliar dados químicos e microbiológicos de água tivamente águas subterrâneas, considerando os subterrânea em região de alta densidade de tan- níveis de coliformes termotolerantes e nutrientes Carroll e Goonetil- ques sépticos (290 sistemas $/ \mathrm{km}^{2}$ ) no estado de (N e P) medidos. Papel importante é desempeleke, 2005 Queensland, Austrália. O desempenho dos TS era nhado pelas chuvas, que carreiam os poluentes muito variável, com alguns sistemas superando 30 durante a recarga do aquífero. Autores alertam anos de idade e com baixos níveis de manuten- para a necessidade de tratamento da água antes do ção. consumo.

Foram analisados parâmetros físico-químicos ( $\mathrm{pH}$, sólidos dissolvidos, OD, condutividade elé- Foram detectados CF em 4 e 14 poços rasos nas trica e temperatura) e biológicos (CT e CF) de 22 estações seca e chuvosa, respectivamente. $\mathrm{O}$ au-

Ejechi et al., 2007 poços rasos em uma região produtora de petróleo da Nigéria para investigar possíveis causas de doenças de veiculação hídrica, como diarréia e febre tifóide. mento significativo de CF durante as chuvas ocorreu em poços rasos construídos próximos a tanques sépticos e que não seguiam as normas de segurança recomendadas.

Estudo utilizou traçador em efluentes de TS para Maior intensidade dos traçadores detectada a suacompanhar o fluxo das águas subterrâneas em deste da área de localização dos tanques sépticos. A um aquífero cárstico do Texas, EUA. Amostras estrutura geológica e as características de recarga

Murray et al., 2007 foram coletadas em 11 poços da região. Na área do aquífero influenciam mais a direção do fluxo do estudada existem 8,7 tanques sépticos/ha, o que efluente nas águas subterrâneas do que o gradiente excede as recomendações da USEPA de 0,5 sis- hidráulico. Nenhuma associação com problemas tema/ha. de saúde.

Nutrientes, isótopos estáveis, 64 compostos orgâ-

nicos de esgotos, 16 compostos farmacêuticos e Água subterrânea com grande vulnerabilidade à

Katz e Griffin indicadores microbiológicos foram usados para contaminação superficial e subsuperficial por múl2008 avaliar o impacto de 9,5 milhões de L/d de eflu- tiplas fontes, incluindo TS, disposição no solo e entes domésticos em uma área de $960 \mathrm{~km}^{2}$, na fertilizantes. Nenhuma associação com problemas qualidade da água subterrânea no norte da Flóri- de saúde da população.

da, EUA.

Duas regiões residenciais vizinhas na costa da

Flórida, EUA, uma conectada a um sistema cen- Período chuvoso: qualidade da água foi impactada tralizado de tratamento de esgoto e outra que pelos efluentes dos TS, quanto aos indicadores utilizava sistema estático, foram comparadas para microbiológicos e nitrato. Período seco: níveis

Meeroff et al., 2008 quantificar a poluição originada de TS. No perío- equivalentes de nutrientes e indicadores patogênido de 2004-2007, 66 amostras foram coletadas e cos observados nas duas regiões. A área conectada analisadas considerando os parâmetros: colifor- ao sistema centralizado mostrou quase o mesmo mes totais, E. coli, Enterococcus, pH, temperatura, nível de poluição nos períodos seco e chuvoso. salinidade, $\mathrm{OD}, \mathrm{NO}_{3}^{-}$e DQO.

Nota: TAS: Sistema de tanque séptico seguido de absorção no solo; TS: tanque séptico 
Quadro 3 - Síntese de pesquisas que reportam área média por sistema e densidade mínima sustentável para sistemas centralizados

\begin{tabular}{|c|c|c|c|}
\hline $\begin{array}{c}\text { Área média } \\
\text { abrangida por } \\
\text { cada sistema }\left(\mathbf{m}^{2}\right)\end{array}$ & $\begin{array}{l}\text { Densidade de } \\
\text { Sistemas } \\
\left(\text { por } \mathbf{k m}^{2}\right) \\
\end{array}$ & Comentários & Referência \\
\hline 65.000 & 15 & $\begin{array}{l}\text { Densidade de tanques sépticos acima deste valor } \\
\text { representa região com potencial problema de } \\
\text { contaminação de águas subterrâneas }\end{array}$ & $\begin{array}{l}\text { USEPA, 1977; Geary e Whitehe- } \\
\text { ad, } 2001\end{array}$ \\
\hline $2.000-4.000$ & $250-500$ & $\begin{array}{l}\text { Modelamento simplificado mostrou aumento da } \\
\text { concentração de } \mathrm{N} \text { abaixo de TAS, quando a } \\
\text { densidade média aumentava. }\end{array}$ & $\begin{array}{l}\text { Perkins, 1984, apud Beal et al., } \\
\text { 2005b. }\end{array}$ \\
\hline $1.000-12.000$ & $85-1.000$ & $\begin{array}{l}\text { Faixa de densidades onde a contaminação da } \\
\text { água subterrânea foi reportada }\end{array}$ & Yates et al, 1986 \\
\hline 10.000 & 100 & $\begin{array}{l}\text { Exemplo de densidade para sistemas não centra- } \\
\text { lizados baseada na capacidade assimilativa de } \\
\text { poluentes mínima (N, P, organismos patogêni- } \\
\text { cos) }\end{array}$ & Jelliffe, 1999 \\
\hline $2.000-4.000$ & $250-500$ & $\begin{array}{l}\text { Baseado nas cargas de aplicação média de nutri- } \\
\text { entes e hidráulica dos sistemas centralizados e } \\
\text { nas distâncias mínimas para remoção de patogê- } \\
\text { nicos. }\end{array}$ & Geary e Gardner, 1998 \\
\hline $50.000-100.000$ & $10-20$ & $\begin{array}{l}\text { Recomendado para áreas ambientalmente sensí- } \\
\text { veis em termos de N e P. }\end{array}$ & $\begin{array}{l}\text { Gerritse, 2002, apud Beal et al., } \\
\text { 2005b }\end{array}$ \\
\hline
\end{tabular}

Fonte: Beal et al., 2005b

Área média $\left(\mathrm{m}^{2} /\right.$ unidade $)=1.000 .000\left(\mathrm{~m}^{2} / \mathrm{km}^{2}\right) /$ densidade $\left(\right.$ unidades $\left./ \mathrm{km}^{2}\right)$

para evitar a contaminação do aquífero por nitratos, vírus e outros microrganismos patogênicos, valor este superior aos listados no Quadro 3. Os autores do presente trabalho não tiveram acesso aos documentos e metodologia que conduziram a tal valor. No entanto, como em todas as normas brasileiras, os valores recomendados refletem um consenso obtido pelos participantes do grupo de trabalho, sendo posteriormente disponibilizados para comentários, durante o período da versão do projeto de Norma. A Norma estabelece ainda os fatores determinantes para o projeto e a utilização do sistema, que abrangem as características do solo, a distância mínima entre o nível de fundo da unidade de infiltração e a superfície do aquífero, a manutenção da condição aeróbia na vala, a distância mínima do poço de captação de água, o processo construtivo, a alternância do uso e o índice pluviométrico.

\section{CONCLUSÕES}

Algumas conexões claras entre sistemas estáticos de tratamento e contaminação de águas superficiais e subterrâneas por nutrientes foram efetuadas
(Quadro 1). Todos estes estudos encontraram alguma ligação causal entre poluição de águas subterrâneas e sistemas estáticos de tratamento de esgotos, principalmente com a infiltração de efluentes de tanques sépticos. No entanto, o grau e o impacto de tais contaminações são ainda pouco esclarecidos. A extensão da contaminação é, também, extremamente variável e pode ser função de vários fatores, tais como: tipo de solo e profundidade da camada não saturada pelo esgoto, qualidade da água subterrânea, número de sistemas de tratamento e disposição na área e distância destes à água subterrânea, velocidade de escoamento no subsolo, fatores climáticos e sazonais, assim como idade e qualidade do projeto dos sistemas de tratamento e disposição.

A preocupação com a contaminação microbiológica por sistemas estáticos de tratamento, principalmente em águas subterrâneas, é ainda maior e tem crescido muito nos últimos anos. No entanto, esta preocupação parece ser baseada mais no aumento do número de sistemas estáticos utilizados em todo o mundo do que nos problemas efetivamente observados. A grande diversidade nos padrões de projeto e construção, a dificuldade de mo- 
nitoramento dos sistemas e as incidências isoladas de contaminação de água subterrânea contribuem para aumentar a preocupação com a sua utilização. No entanto, nos locais onde foram verificadas associações entre doenças de veiculação hídrica e sistemas estáticos de tratamento, estes eram simples e mal operados (Quadro 2). Os impactos cumulativos ao longo do tempo e a efetiva influência dos organismos realmente patogênicos não têm sido adequadamente investigados e/ou reportados devido a dificuldades econômicas e logísticas nas determinações de campo e nas técnicas laboratoriais de enumeração das espécies de organismos patogênicos, principalmente em países em desenvolvimento. No entanto, observa-se que modelos de escoamento e de qualidade das águas subterrâneas têm se mostrado ferramentas úteis e vêm sendo utilizados cada vez mais por diversos pesquisadores em todo o mundo.

Diversos autores ressaltam, ainda, que a contaminação pode ocorrer tanto em locais que utilizam sistemas centralizados quanto descentralizados de tratamento de esgotos. Grande parte dos países desenvolvidos que utilizam, predominantemente, os sistemas dinâmicos, também enfrentam tais problemas, uma vez que estes também podem estar associados a problemas ambientais e de saúde pública. Algumas situações usualmente relatadas incluem (a) sistemas de coleta incompletos ou inadequados, (b) linhas de interceptação insuficientes e sem interligação com a estação de tratamento de esgotos, (c) tratamento de esgotos incompleto ou ineficiente, (d) tratamento de esgotos insuficiente em termos das demandas do corpo d'água receptor em função de sua classe de enquadramento, (e) tratamento de esgotos sem desinfecção e (e) gerenciamento inadequado do lodo produzido.

\section{AGRADECIMENTOS}

SEPLAG - Secretaria de Estado de Planejamento e Gestão de Minas Gerais

\section{REFERÊNCIAS}

ASSOCIAÇÃO BRASILEIRA DE NORMAS TÉCNICAS. NBR 13969: Tanques sépticos - Unidades de tratamento complementar e disposição final dos efluentes líquidos - Projeto, construção e operação. Rio de Janeiro, $1997.60 \mathrm{p}$.
ALHAJJAR, B.J.; STRAMER, S.L.; CLIVER, D.O.; HARKIN, J.M. Transport modelling of biological tracers from septic systems. Water Research, 22, 907-915, 1988.

AL-KHASHMAN, O. A. Study of water quality of springs in Petra region, Jordan: A three-year follow-up. Water Resource Management, v. 21, pp. 1145-1163, 2007.

ARNADE L. J. Seasonal Correlation of Well Contamination and Septic Tank Distance. Ground Water, v. 37, n. 6, pp. 920-923, 1999.

ARGOSS. Guidelines for assessing the risk to groundwater from on-site sanitation. British Geological Survey Commissioned Report CR/01/42. British Geological Survey, Wallingford, UK, 2001.

BEAL, C. D.; GARDNER, E. A.; MENZIES, N. W. Process, performance, and pollution potential: A review of septic tank-soil absorption systems. Australian Journal of Soil Research, 43 (7), 781-802, 2005.

BEAL, C. D.; GARDNER, E. A.; MENZIES, N. W. Predicting the failure of septic tank - soil absorption systems: A step closer to managing water quality in non-sewered catchments. In 'International River Symposium 2005'. Brisbane, Aust. 6 - 9 September 2005b.

BOPP, D.J.; SAUDERS, B.D.; WARING, A.L.; ACKELSBERG, J.; DUMAS, N. Detection, isolation and molecular subtyping of Escherichia coli 0157:H7 and Campylobacter jejuni associated with a large waterborne outbreak. Journal of Clinical Microbiology, 41, 174-180, 2003.

BORCHARDT, M.A.; CHYOU, P.; DE VRIES, E.O.; BELONGIA, E.A. Septic system density and infectious diarrhea in a defined population of children. Environmental Health Perspectives, 111, 742-747, 2003.

CARROLL, S.; GOONETILLEKE, A. Assessment of high density of onsite wastewater treatment systems on a shallow groundwater coastal aquifer using PCA. Environmetrics, v.16, Issue 3, Pages 257 - 274, 2005.

CARROLL, S.; GOONETILLEKE, A.; THOMAS, E.; HARGREAVES, M.; FROST, R.; DAWES, L. Environmental Assessment: Integrated Risk Framework for Onsite Wastewater Treatment Systems. Environmental Management, V. 38, N. 2, pp. 286-303, 2006.

CHIDAVAENZI, M.; BRADLEY, M.; JERE, M.; NHANDARA, C. Pit latrine effluent infiltration into groundwater: the Epworth case study. In: CHORUS, I., RINGELBAND, U., SCHLAG, G., SCHMOLL, O. (eds) (2000). Water, Sanitation and Health. IWA Publishing, World Health Organization Series, pp. 171-177, 2000.

CHOI, W. J.; HAN, G. H.; LEE, S. M.; LEE, G. T.; YOON, K. S.; $\mathrm{CHOI}, \mathrm{S}$. M.; RO, H. M. Impact of land-use types on nitrate concentration and $\mathrm{d} 15 \mathrm{~N}$ in unconfined groundwater in rural areas of Korea. Agriculture, Ecosystems \& Environment, v. 120, Issues 2-4, pp. 259-268, 2006. 
COLE, M. L.; KROEGER, K. D.; MCCLELLAND, J. W.; VALIE$L A, I$. Effects of watershed land use on nitrogen concentrations and d15 nitrogen in groundwater. Biogeochemistry, v. 77, n. 2, pp. 199-215, 2006.

CORNIELLO, A.; DUCCI, D.; RUGGIERI, G. Areal Identification of Groundwater Nitrate Contamination Sources in Periurban Areas. Journal Soils Sediments, v. 7 , n.3, pp. 159-166, 2007.

COTTON, A.; SAYWELL, D. On-plot sanitation in low-income urban communities: guidelines for selection, WEDC, Loughborough University, UK, 1998.

DAY, L. Septic systems as potential pollution sources in the Cannonsville Reservoir watershed, New York. Journal of Environmental Quality, 33, 1989-1996, 2004.

DeBORDE, D.C.; WOESSNER, W.W.; LAUERMAN, B.; BALL, P.N. Virus occurrence and transport in a school septic system and unconfined aquifer. Ground Water, 36 (5), 825-834, 1998.

DILLON, K.S.; CORBETT, D.R.; CHANTON J.P.; BURNETT, W.C.; KUMP, L. Bimodal transport of a waste water plume injected into saline ground water of the Florida Keys. Ground Water, 38 (4), 624-634, 2000.

EJECHI, B. O; OLOBANIYI, S. B.; OGBAN, F. E.; UGBE, F. C. Physical and Sanitary Quality of Hand-Dug Well Water from Oil-Producing Area of Nigeria. Environmental Monitoring Assessment. v. 128, n. 1-3, pp. 495501, 2007.

EPA (Environmental Protection Agency). The report to Congress - Waste disposal practices and their effects on ground water. U. S. Environmental Protection Agency, Washington D.C., 1977.

FAYE, S. C.; FAYE, S.; WOHNLICH, S.; GAYE, C. B. An assessment of the risk associated with urban development in the Thiaroye area (Senegal). Environmental Geology, v. 45, n. 3, pp. 312-322, 2004.

FRANCEYS, R.; PICKFORD, J.; REED, R. A guide to the development of on-site sanitation. WHO, Geneva, 1992.

GEARY, P.M.; GARDNER, E.A. Sustainable on-site treatment systems. In 'On-site wastewater treatment. Proceedings of the 8th National Symposium on Individual and Small Community Sewage Systems'. Orlando, FL. (ASAE: St Joseph, MI), 1998.

GEARY, P.M.; WHITEHEAD, J.H. Groundwater contamination from on-site domestic wastewater management systems in a coastal catchment. In On-Site Wastewater Treatment, Proc. Ninth Natl. Symp. on Individual and Small Community Sewage Systems, Fort Worth, Texas, USA, pp. 479-487, 2001.

GERRITSE, R.G. Movement of nutrients from onsite wastewater systems in soils. Geoprocc Pty Ltd prepared for Department of Health, Western Australia, May 28, 2002, apud BEAL, C. D.; GARDNER, E. A.; MENZIES, N. W. Process, performance, and pollution po- tential: A review of septic tank-soil absorption systems. Australian Journal of Soil Research, 43 (7), 781-802, 2005.

GONDA, J. Contaminação de solos e de águas do lençol freático por fossas absorventes. 1985. 87 f. Dissertação (Mestrado em Hidráulica e Saneamento) - Escola de Engenharia de São Carlos, Universidade de São Paulo, São Carlos, 1985.

HARMAN, J.; ROBERTSON, W.D.; CHERRY, J.A.; ZANINI, L. Impacts on a sand aquifer from an old septic system: nitrate and phosphate. Ground Water, 34, 11051114, 1996.

HARRISON, R. B.; TURNER, N. S.; HOYLE, J. A.; KREJSL, J.; TONE, D. D.; HENRY, C. L.; ISAKSEN, P. J.; XUE, D. Treatment of Septic Effluent for Fecal Coliform and Nitrogen in Coarse-textured Soils: Use of Soil-only and Sand Filter Systems. Water, Air, \& Soil Pollution, v. 124, n. 1-2, 2000.

HELLER, L.; CHERNICHARO, C. A. L. Tratamento e disposição final dos esgotos no meio rural. In: Seminário Internacional Tendências no Tratamento Simplificado de Águas Residuárias Domésticas e Industriais, 1996, Belo Horizonte. Anais...Belo Horizonte: Departamento de Engenharia Sanitária e Ambiental, 1996. p. $168-221$

HOGYE, S.; RUBIN, A. R.; HUDSON, J. Development of EPA guidelines for management of onsite/decentralized wastewater systems. In On-Site Waste water Treatment, Proc. Ninth Natl. Symp. On Individual and Small Community Sewage Systems, Fort Worth, Texas, USA, pp. 470-478, 2001.

HOWARD, G.; ABBT-BRAUN, G.; FRIMMEL, F.; MCCHESNEY, D.; REED, B. WHO: Protecting Ground Water for Health: Managing the Quality of Drinking-water Sources. Nonserial Publication. Cap. 9. ISBN, 924 154668 9. IWA Publishing, 2006b.

HOWARD, G.; REED, B.; McCHESNEY, D. WHO: Protecting Ground Water for Health: Managing the Quality of Drinking-water Sources. Nonserial Publication, Cap. 21. ISBN, 924154668 9. IWA Publishing, 2006a.

JALALI, M. Hydrochemical Identification of Groundwater Resources and Their Changes under the Impacts of Human Activity in the Chah Basin in Western Iran. Environmental Monitoring Assessment, v. 130, n. 13, pp. 347-364, 2007.

JELLIFFE, P.A. Developments in determining critical lot density for the protection of water quality. In 'Proceedings of On-site '99 Conference: Making on-site wastewater systems work'. University of New England, Armidale, NSW. (Ed. A Patterson Robert) pp. 191-198, 1999.

JIN, Z.; CHEN, Y.; WANG, F.; OGURA, N. Detection of nitrate sources in urban groundwater by isotopic and chemi- 
cal indicators, Hangzhou City, China. Environmental Geology, v. 45, n. 7, pp. 1017-1024, 2004.

KATZ, B. G.; GRIFFIN, D. W. Using chemical and microbiological indicators to track the impacts from the land application of treated municipal wastewater and other sources on groundwater quality in a karstic springs basin. Environmental Geology, 2008.

KELSEY, H.; PORTER, D. E.; SCOTT, G.; NEET, M.; WHITE, D. (2004). Using geographic information systems and regression analysis to evaluate relationships between land use and fecal coliform bacterial pollution. Journal of Experimental Marine Biology and Ecology, v. 298, n. 2, pp. 197-209, 2004.

LIPP, E.K.; FARRAH, S.; ROSE, J.B. Assessment and impact of microbial fecal pollution and human enteric pathogens in a coastal community. Marine Pollution Bulletin, 42 (4), 286-293, 2001.

L'HIRONDEL, J.; L'HIRONDEL J.L. 'Nitrate and man. Toxic, Harmless or Beneficial?.' (CABI Publishing: Wallingford, UK), 2002, apud BEAL, C. D.; GARDNER, E. A.; MENZIES, N. W. Process, performance, and pollution potential: A review of septic tank-soil absorption systems. Australian Journal of Soil Research, 43 (7), 781-802, 2005.

MEEROFF, D. E.; BLOETSCHER, F.; BOCCA, T.; MORIN, F. Evaluation of Water Quality Impacts of On-site Treatment and Disposal Systems on Urban Coastal Waters. Water Air Soil Pollution, DOI 10.1007/s11270-008-9630-2, 2008.

MURRAY, K. E.; STRAUD, D. R; HAMMOND, W. W. Characterizing groundwater flow in a faulted karst system using optical brighteners from septic systems as tracers. Environmental Geology, v. 53, pp. 769-776, 2007.

NICOSIA, L. A., J. B. ROSE, AND M. T. STEWART. A field study of virus removal in septic tank drain fields. Journal of Environmental Quality, v. 30, n.6, pp. 1933-1939, 2001.

PANG, L.; CLOSE, M.; GOLTZ, M.; SIMON, L.; DAVIES, H., HALL, C.; STANTON, G. Estimation of septic tank setback distances based on transport of $E$. coli and F-RNA phages. Environment International, 29, 907921, 2003.

PERKINS, R.J. Septic tanks, lot size and pollution of water table aquifers. Journal of Environmental Health, 46, 298-304, 1984, apud BEAL, C. D.; GARDNER, E. A.; MENZIES, N. W. Process, performance, and pollution potential: A review of septic tank-soil absorption systems. Australian Journal of Soil Research, 43 (7), 781-802, 2005.

PRADHAN, S.; HOOVER, M. T.; AUSTIN, R.; DEVINE, H. A. Potential nutrient loadings from on-site systems to watersheds. In On-Site Wastewater Treatment X,
Conference Proceedings, Sacramento, California USA, pp. 441-450, 2004.

SIEGRIST. R.; TYLER, E. J.; JENSSEN, P. D. Design and performance of onsite wastewater soil absorption systems. In 'National Research Needs Conference Proceedings: Risk Based Decision Making for Onsite Wastewater Treatment'. EPRI Palo Alto, CA U.S. Environmental Protection Agency and National Decentralized Water Resources Capacity Development Project, 2001, 1101446, p. 48, 2000.

STEFFY, L.Y.; KILHAM, S. Elevated $\delta^{15} \mathrm{~N}$ in stream biota in areas with septic tank systems in an urban watershed. Ecological Applications, v.14, n. 3, 637-641, 2004.

TONG, S.T.; CHEN, W. Modeling the relationship between land use and surface water quality. Journal of Environmental Management, 66 (4), 377-393, 2002.

TUTHILL, A.; MEIKLE, D.; ALAVANJA, M. Coliform bacteria and nitrate contamination of wells in major soils of Frederick, Maryland. Journal of Environmental Health, 60 (8), 16-20, 1998.

USEPA. Waste disposal practices and their effects on ground water. Office of Water Supply and Office of Solid Waste Management Programs, U.S. Environmental Protection Agency EPA - 570/9-77-001, 1977.

VAN CUYK, S.; SIEGRIST, R. L. Pathogen fate in wastewater soil absorption systems as affected by effluent quality and soil clogging genesis. In On-Site Wastewater Treatment: Proc. 9th Nat. Symp. Individual and Small Community Sewage Systems, Fort Worth, Texas, USA, pp. 125-136, 2001.

VARNIER, C.; HIRATA, R. Contaminação da água subterrânea por nitrato no Parque Ecológico do Tietê - São Paulo, Brasil. Revista Águas Subterrâneas, n. 16, 2002.

VAUGHN, J.M.; LANDRY, E.F.; MCHARRELL, T.Z.. Entrainment of viruses from septic tank leach fields through a shallow, sandy soil aquifer. Applied and Environmental Microbiolog, v. 45, n.5, 1474-1480 y, 1983.

WHITEHEAD, J.H.; GEARY, P.M. Geotechnical aspects of domestic on-site effluent management systems. Australian Journal of Earth Sciences, 47 (), 75-82, 2000.

WHITEHEAD, J.H.; GEARY, P.M.; SAUNDERS, M. Towards a better understanding of sustainable lot density-evidence from five Australian case studies. In 'Onsite '01: Proceedings of On-site '01 Conference'. University of New England, Armidale, NSW, pp. 383390, 2001.

WHO. Guide to on-site sanitation. Part 1: Foundations of sanitary practice. World Health Organization, 1992.

WHO/UNICEF. Water for life: Making it happen. World Health Organization, Geneva, and the United Nations Childrens Fund, New York, Joint Monitoring Programme 
for Water Supply and Sanitation, 2005. ISBN 924 1562935

YATES, M. V. Septic Tank Density and Groundwater Contamination. Groundwater, 23, 586-591, 1985.

YATES, M. V.; YATES, S. R.; WARRICK, A. W.; GERBA, C. P. Use of Geostatistics to Predict Virus Decay Rates for Determination of Septic Tank Setback Distances. Applied and Environmental Microbiology, Vol. 52, No. 3, p. 479-483, 1986.

Potential Impacts of On-Site Sewerage Systems on Groundwater - Review of Literature

\begin{abstract}
This review of literature compiles several studies investigating the potential impacts of on-site sewerage systems on groundwater contamination, mainly by nitrates and pathogens. Some clear connections have been reported in several studies, but the degree and impact of such contamination are poorly understood. The extent of contamination is extremely variable and may be a function of soil conditions, type of treatment system, wastewater loading rates, aquifer characteristics and water level. Consequently, the design, construction and proper maintenance of these systems are crucial to a successful and sustainable operation. Evidence of aquifer contamination seem to be based more on the increasing number of on-site systems worldwide than on the problems actually observed that are directly associated with this type of technology.

Key-words: On-site sewage systems, groundwater, contamination, pathogenic organisms, nitrate.
\end{abstract}

